\title{
Compressive characteristics of metal matrix syntactic foams
}

Imre Norbert ORBULOV ${ }^{\mathrm{a}, 1}$, János GINSZTLER ${ }^{\mathrm{a}}$

${ }^{a}$ Research Group for Metals Technology of Hungarian Academy of Sciences,

Bertalan Lajos utca 7., 1111, Budapest, Hungary

${ }^{1}$ Corresponding author

E-mail: orbulov@eik.bme.hu

Phone: +3614632386

Fax: +3614631366

Cell: +36 705139944

Postal address: Research Group for Metals Technology of Hungarian Academy of Sciences, Bertalan Lajos utca 7., 1111, Budapest, Hungary

Published in: Composites Part A 43 (2012) 553-561, doi:10.1016/j.compositesa.2012.01.008

Keywords: A: Foams, A: Metal-matrix composites (MMCs), B: Mechanical properties, B: Strength 


\begin{abstract}
The compressive behaviour of eight different metal matrix syntactic foams (MMSFs) are investigated and presented. The results showed that the engineering factors as chemical compositions of the matrix material, the size of the microballoons, the previously applied heat treatment and the temperature of the compression tests have significant effects on the compressive properties. The smaller microballoons with thinner wall ensured higher compressive strength due to their more flawless microstructure and better mechanical stability. According to the heat treatments, the T6 treatments were less effective than expected; the parameters of the treatment should be further optimized. The elevated temperature tests revealed $\sim 30 \%$ drop in the compressive strength. However, the strength remained high enough for structural applications; therefore MMSFs are good choices for light structural parts working at elevated or room temperature. The chemical composition - microballoon type - heat treatment combinations give good potential for tailoring the compressive characteristics of MMSFs.
\end{abstract}

Keywords: A. Foams; A. Metal-matrix composites (MMCs); B. Mechanical properties; B. Strength

\title{
1 Introduction
}

Nowadays metallic foams become more and more important and this is confirmed by the increasing number of papers published on this topic. The 'conventional' metallic foams, which consist of a metal structure, a gas phase and stabilising particles, have 
wide spread literature thanks to their potential application possibilities as automotive parts, energy absorbers etc. or blast and collision damping elements in buildings or vehicles etc. However there are still existing problems for example in the foaming process $[1,2]$. The metallic foams have a special class, namely the metal matrix syntactic foams (MMSFs). The MMSFs have numerous perspective applications as covers, hulls, walls, castings, or in automotive and electromechanical industry sectors because of their high energy absorbing and damping capability (both blasts and vibrations) and due to their low density. In the MMSFs the porosity is ensured by the incorporation of ceramic microballoons $[3,4]$. The microballoons are commercially available and they contain mainly various oxide ceramics $[5,6]$. The quality of the microballoons (uniform wall thickness and flawless wall) has a strong effect on the mechanical and other properties of the foams.

The MMSFs can be produced by pressure infiltration or by stir casting; both ways are common in the literature. The main mechanical loading mode of MMSFs is compression; therefore the compression characteristics have been investigated in some aspects. Palmer et al. studied the pressure infiltration process and mechanical behaviour of various microballoon and metal matrix combinations. Compressive stress-strain data were gathered for foams prepared from combinations of Al1350, Al5083 and Al6061 alloys for both $45 \mu \mathrm{m}$ and $270 \mu \mathrm{m}$ spheres [7]. Balch et al fabricated aluminium matrix MMSFs by liquid metal infiltration of commercially pure (cp-Al) and Al7075 aluminium. The cp-Al foam exhibited peak strengths in compression of over $100 \mathrm{MPa}$, with a uniform densification plateau of $60 \%$ strain. The Al7075 matrix foams had significantly higher peak strengths_(up to $230 \mathrm{MPa}$ ) than $\mathrm{cp}-\mathrm{Al}$ based ones, up to $230 \mathrm{MPa}[8,9]$. Rohatgi et al investigated the pressure 
infiltration technique of nickel coated and uncoated microballoons. In their other work loose beds of microballoons (cenospheres) were pressure infiltrated with A356 alloy melt to fabricate MMSFs. The volume fractions of microballoons in the composites were in the range of $20-65 \%$, the processing variables included melt temperature, gas pressure and the size of microballoons. The effect of these processing variables on the microstructure and compressive properties of the synthesized composites was characterized $[10,11]$. Kiser et al performed investigations on the mechanical response of a family of MMSFs under both uniaxial compression and constrained die compression loadings. The key material parameters that varied were the matrix strength and the ratio of wall thickness to radius of the microballoons. They observed that the energy absorption capacity was extremely high in comparison with values that are typical of metal foams [12]. Wu et al established a new method to predict the compressive strength of MMSFs, showing the relation between the relative wall thickness of the microballoons and the compressive strength of such foams. The tests indicated that MMSFs can deform plastically at a relatively higher stress (45-75 MPa); the deformation mechanisms of syntactic foams had also been discussed [13]. Tao et al investigated the mechanical properties of MMSFs with monomodal and bimodal distribution of microballoons. By combining fine and coarse microballoons, the density of bimodal MMSFs can be decreased by up to $25 \%$. The bimodal foams have the advantages of a flat plateau regime, high plateau stress and good ductilityIn next step Al matrix syntactic foams with additional Al particles embedded were fabricated by pressure infiltration. With the introduction of Al particles, the ductility of the syntactic foams was significantly increased and the compressive strength alse increased by up to $30 \%[14,15]$. Zhang et al manufactured aluminium matrix syntactic foams with low-cost porous ceramic spheres of diameters between 0.25 
and $4 \mathrm{~mm}$ by pressure infiltration casting. The mechanical response of the syntactic foamsMMSFs with different sphere sizes and densities under static and dynamic conditions was investigated. They found that the plateau strength and thus the amount of energy absorption of the syntactic foamMMSFs were largely determined by the volume fraction of $\mathrm{Al}$ and to a lesser extent by the mechanical properties of the ceramic spheres in the foam [16]. In the works of Mondal et al microballoons in the range of 30-50 vol\% were used as space holders-for making syntactic aluminium foam using stir-casting technique. The synthesized MMSF was characterized in terms of microstructures, hardness and compressive deformation behaviour. The compressive deformation behaviour was similar to those of conventional low density aluminium foam. However, the They found the plateau stress of these MMSFs is considerably higher than those of conventional aluminium foams. The dry sliding wear behaviour of MMSFs has been also studied using a pin-on-disc apparatus [17, 18]. Rabiei and O'Neill produced MMSFs reinforced by hollow steel spheres using gravity casting techniques. The foam was comprised of steel hollow spheres packed into a random dense arrangement, with the interstitial space between spheres infiltrated with a casting aluminium alloy. The aluminium composite foam developed in the study displayed superior compressive strength and energy absorption capacity [19]. Ramachandra and Radhakrishna synthesized aluminium based MMSFs containing up to $15 \mathrm{wt} \%$ of microballoons by stir casting method. The properties like density, hardness, microhardness, ductility and ultimate tensile strength were investigated. The MMSFs produced was also subjected to corrosion, dry sliding wear and slurry erosive wear test. The addition of microballoons reduced the density of composites while increased some of their mechanical properties. The results of wear studies have shown that the resistance to wear increased with increase in 
percentage of microballoons-[20, 21]. Daoud used different, not aluminium based matrix materials to produce MMSFs. For example MMSFs with ZnAl22 matrix was produced by stir casting method. The foam composites containing microballoons showed superior compressive properties and energy absorption compares to those of the conventional foams [22]. In the work of Couteau and Dunand aluminium syntactic foams with densities of $1.2-1.5 \mathrm{~g} / \mathrm{cm}^{3}$ were deformed at $500^{\circ} \mathrm{C}$ under constant uniaxial compressive stresses ranging from 5 to $14 \mathrm{MPa}$. The foam's creep behaviour was characterized by a short primary stage and a long secondary stage where the strain rate was constant and minimum, followed by a tertiary stage at high stresses [23].

The modelling of the MMSFs has been also studied. Bardella and Genna proposed a complex numerical method to predict the elastic properties of the MMSFs. Explicit formulae for the homogenized values of the elastic moduli of the MMSFs were derived-[24, 25]. A similar model was used by Marur to compute the effective elastic moduli of syntactic foams. having perfect adhesion between the inclusion and the matrix. The computed effective elastic moduli are between the bounds, but usually overestimate the experimental data. Due to this the assumption of perfect adhesion between the inclusion and the matrix is relaxed to allow possible localized slip and separation at the particle interface. The analytical results obtained considering imperfect interface between microballoons and matrix well agree with the measured elastic modulus reported in the literature [26, 27]. Sanders and Gibson presented models for the mechanical properties of foams suggest that closed-cell foams should have significantly higher modulus and strength than open-cell foams, especially at low relative densities. The elastic moduli and initial yield strength of MMSFs were 
analysed too. The results indicated that their theoretical values of moduli and strength are intermediate to those for open- and closed-cell foams [28].

Most of the MMSFs are produced by pressure infiltration; therefore the infiltration parameters (like required threshold pressure) have been also studied. Trumble presented an analysis of spontaneous infiltration of model non-cylindrical pores. The approach is based on the simple notion that the liquid will penetrate non-cylindrical pores until the contact angle with the pore surface is established coincident with a flat liquid surface-_29]. Bárczy and Kaptay developed a new infiltration model for "closely packed equal sphere - CPES" structure. In their study the threshold pressure, the threshold contact angle and the equilibrium height of penetration has been determined. All these parameters are significantly different from those, obtained from the traditional capillary penetration model, but similar to Garman model. The experiments demonstrated the reliability of the theoretical results [30]. Asthana et al also overviewed some fundamental materials phenomena relevant to infiltration processing of metal-matrix composites. They stated that the lack of comprehensive theoretical framework induce further research efforts to be done-[31].

The aim of this paper is to extend the knowledge about MMSFs by analysing and characterizing new matrix materials, the effect of the microballoon size, the effects of heat treatment and elevated test temperature.

\section{Investigated materials and production methods}

Overall eight types of MMSFs were produced by pressure infiltration from the combination of four matrix materials (Al99.5, AISi12, AIMgSi1 and AICu5) and two 
ceramic microballoons (SL150 and SL300). The chemical compositions of the matrices are listed in Table 1, in which the approximated ultimate tensile strengths of the materials in annealed $(\mathrm{O})$ and heat treated (T6) conditions are also presented only for rough strength comparison. The SL150 and SL300 microballoons were manufactured and provided by Envirospheres Pty- Ltd- [6]. The main differences between the two types are in the average diameter, density and wall thickness. Their main parameters are summarized in Table 2 . The MMSFs were produced by pressure infiltration in a special infiltration chamber (Fig. 1). In the first step the

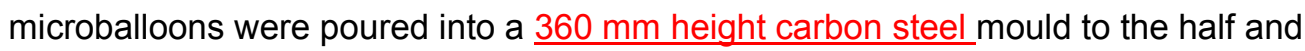
they were densified by gentle tapping and knocking to get randomly closed pack structure (RCPS). The cross-section of the mould was $40 \times 60 \mathrm{~mm}$ and its inner surface was coated by a thin graphite layer in order to easier specimen removal. The maximal volume fraction can be reached with quasi-equal diameter spheres is 64 vol\%, as it is published in [32]. After this a layer of alumina mat separator was placed on the top of the microballoons and a block of matrix material was put on the mat. The mould was situated into the infiltration chamber, the chamber was closed and the whole system was evacuated by a vacuum pump (rough vacuum). The proper heating was ensured by three heating zones and the temperatures of the matrix block and the microballoons were continuously monitored by two thermocouples. After the melting of the matrix the molten material formed a liquid cork in the mould above the separator layer. Tthe vacuum pump was switched off and argon gas was let into the chamber with a previously set pressure. Due to this a pressure difference was built up between the inner space of the mould (vacuum under the liquid cork) and the chamber (argon pressure). This pressure difference forced the molten metal to infiltrate into the space between the microballoons. After complete solidification the 
mould was removed from the chamber and water cooled to room temperature. Then the complete MMSF block $(\sim 40 \times 60 \times 180 \mathrm{~mm})$ could be removed from the mould. For further details about the production process please refer to [4].The blocks were designated by their constituents: for example AI99.5-SL150 stands for an MMSF block with Al99.5 matrix and with $\sim 64$ vol\% SL150 microballoons. The main physical properties, such as density and porosity are presented in Table 3. The theoretical densitiesy were calculated by the rule of mixtures (eq. 1).

$\rho_{t}=V_{m b} \rho_{m b}+\left(1-V_{m b}\right) \rho_{m}$

Where $V_{m b}$ is the volume fraction of the microballoons (64 vol\% in every case), $\underline{\rho}_{\underline{m b}}$ is the density of the microballoons (from Table 2 ) and $\rho_{\underline{m}}$ is the density of the matrix material (from Table 1). The measured densities ( $\rho_{\text {meas }}$ ) were determined by

Archimedes' method. andThe microballoon-porosity (the porosity in the MMSF blocks ensured by the hollow microballoons, $\mathrm{P}_{\mathrm{mb}}$ ) were-can be calculated from the average geometrical parameters of the microballoonsas the original porosity of one average microballoon $\left(\mathrm{P}_{1 \mathrm{mb}}\right)$ multiplied by the volume fraction of the microballoons $\left(\underline{V}_{\underline{m b}}\right)$. The original porosity of one microballoon $\left(\mathrm{P}_{1 \mathrm{mb}}\right)$ is its inner volume divided by its whole volume. Thus

$P_{m b}=V_{m b}\left(\frac{\frac{4 \pi}{3} r_{i}^{3}}{\frac{4 \pi}{3} r_{o}^{3}}\right)=V_{m b}\left(\frac{r_{i}}{r_{o}}\right)^{3}$

Where $V_{m b}$ is the volume fraction of the microballoons (64 vol\% in our case), $r_{i}$ and $r_{0}$ are the average inner and outer radii of the microballoon respectively (from Table 2). The matrix porosities-porosity $\left(\underline{P}_{\underline{m}_{2}}\right.$ the volume of the pores in the matrix material ${ }_{2}$ (for 
example between the microballoons, due to insufficient infiltration) can be calculated for the whole volume as:

$P_{m}=\frac{\rho_{t}-\rho_{\text {meas }}}{\rho_{t}}$

Formázott: Betütípus: (Alapérték) Arial, 12 pt

Formázott: Tabulátorok: $16 \mathrm{~cm}$, Jobbra zárt

divided by the volume of the whole specimen) were calculated as the difference between theoretical and measured density divided by the theoretical density. The negative matrix porosity refers to infiltrated microballoons (the microballoon-porosity should be decreased). The values of matrix porosity are always remained below $7.2 \%$, so the infiltration can be qualified as a suitable one. The total porosity $\left(\mathrm{P}_{\mathrm{t}}\right)$ is the sum of the microballoon porosity and the matrix porosity.

\section{ExperimentsMeasurements}

The main loading mode of foam materials is the compression; therefore compression tests were performed on cylindrical specimens. The diameter and the height of the specimens were 14 and $21 \mathrm{~mm}$ respectively $(H / D=1.5)$. The compression tests were performed on a MTS 810 type universal testing machine in a four pillar tool at room temperature. The surfaces of the tool were grinded and polished. The specimens and the tool were lubricated with anti-seize material. The test speed was $0.15 \mathrm{~mm} / \mathrm{s}$, which ensured quasi-static compression. Six specimens were compressed until 50\% engineering strain from each MMSF type to get representative results.

Annealed specimens were compressed in the case of all matrix and microballoon combination $(8 \times 6=48$ specimens $)$. In the case of heat-treatable matrix materials (AIMgSi1 and AICu5) T6 heat treatment was done (according to ASM, see Table 4 
[33]) and heat treated specimens were also compressed $(+4 \times 6=+24$ specimen). The annealed and heat treated results were compared to get information about the effect of heat treatment. In the case of not heat-treatable matrices (Al99.5 and AISi12) the compression tests were performed both at room and elevated temperature $\left(220^{\circ} \mathrm{C}\right.$, above the 0.5 homologous temperature, again $+4 \times 6=+24$ specimens). The aim of these tests was to figure out, how the MMSFs would perform as structural elements at higher temperature.

In summary 96 compression tests were performed and evaluated in accordance with the ruling standard about the compression tests of cellular materials [34]. This gives sufficient data for statistical evaluation of the results and trends.

The phase composition of MMSFs was determined by X-ray diffraction Formázott: Betútípus: 12 pt measurements (XRD). For this purpose a Phillips X-Pert type diffractometer with 35 $\underline{\mathrm{mA} \text { cathode heating current and copper anode (CuKa, } \lambda=0.154186 \mathrm{~nm} \text { ) with } 40 \mathrm{kV}}$ voltage was used. The rotating speed of goniometer was 0.04 degree/s.

For the investigation of the interface zone between microballoons and the matrix material line energy dispersive X-ray spectroscopy (line-EDS) was performed by a Phillips XL-30 type scanning electron microscope equipped with an EDAX Genesis EDS analyser. The excitation voltage was $20 \mathrm{kV}$, one hundred points were measured along the lines, each point was excited for $20 \mathrm{~s}$ with 35 us detector acquisition rate.

\section{Results and discussion}

The load bearing capacity of MMSFs depends on many parameters, such as the chemical composition of the matrix, the type of the microballoons, the test 
temperature or the previous heat treatments. In order to characterize these effects we have done numerous compression tests as described in the previous section. During the tests the engineering stress - engineering deformation curves were plotted like in Fig. 2. As an example Fig. 2 shows the graph for an AIMgSi1-SL150 MMSF specimen tested at room temperature and in annealed condition. Gupta et al [35] and Bunn and Mottram [36] have investigated polymer matrix syntactic foams with similar stress - strain diagrams. According to the results of Gupta et al the general stress - strain curves were divided into three parts [35]. Based on their idea the diagram of MMSFs can be divided into three main parts containing overall five sections. In the first section (from point A to B) the specimens were deformed elastically only. In this section the microballoons remained unharmed as it can be observed in Fig. $2 a$ and $2 b$; there are no cracks at all. The overall deformation is related to the elastic deformation of the composite. The slope of the first part is defined as structural stiffness (S (MPa), see [34] about the standardized compression test of cellular materials). The stiffness is one of the characterizing properties of the MMSFs. In the vicinity of point A the deviation from the fitted dashed line can be caused by the internal sliding of the material or by the springs and the natural movement of the sliding parts of the tool. Due to this it should be distracted from the measured strain. In the second section from point $B$ to $C$ the plastic deformation of the matrix began. The load transfer between the matrix and the microballoons increased to its maximum, but the microspheres remained still unharmed. At the end of this section at point $C$ the stress reached the compressive strength $\left(\sigma_{c}(\mathrm{MPa})\right)$ at the fracture strain $\left(\varepsilon_{\mathrm{c}}(\%)\right)$. These parameters are also important characterizing properties, because they show the load bearing capacity of the MMSFs directly. At point $C$ the first crack appeared in the specimen. This first rupture was very thin and 
very sharp and only one row of the microballoons was cracked as it is shown in Fig. 2c. The plane of the crack closed $\sim 45^{\circ}$ with the horizontal direction, because in the case of uniaxial loading the maximum shear load appears in this direction. The stress suddenly dropped to point $\mathrm{D}$ due to the reduced load bearing capacity caused by the fracture of the microballoons and the movement of the recently formed specimen halves. From point $D$ to $E$ the fracture band expanded and the crack became thicker. The neighbouring microballoons broke and the load bearing capacity decreased further, but more slowly due to the friction between the specimen halves (Fig. 2d). This deformation phenomenon consumed significant strain and mechanical energy due to the fracture of the ceramic microballoons and due to the plastic deformation of the matrix. The absorbed mechanical energy is the fourth main characterizing parameter of the MMSFs, as it indicates the damping and protecting capability of the MMSFs against a blast, collision or simple vibration. The absorbed energy is equal to the area under the recorded stress-strain curve and can be integrated numerically. From point $E$ the complete densification of the specimens took place. At the end of this process the cavities of the broken microballoons were filled up by the matrix material due to its plastic deformation (Fig. 2e). This part - also called plateau region - absorbs lot of energy, because it is relatively long and has high stress value. The shape of the diagrams after point $E$ can be ascending or constant (usually ascending because the densifying material needs higher force to be deformed). It may contain larger drops or local maximums due to secondary cracks. The process ended at $50 \%$ engineering strain when the test stopped (point F in Fig. 2). One of the compressed specimens was grinded to its half diameter and shown in Fig. 3a. The fracture band appeared under $\sim 45^{\circ}$ as it is expected from the maximum shear stress theory, mentioned above. One can observe the shear band was rather wide and very well 
defined. However the remaining part of the specimen was unharmed and this part would be able to absorb further energy if the compression was continued. In Fig. 3b a magnified picture about the sharp margin between the densified and unharmed region is shown. In summary the structural stiffness, compressive strength, fracture strain and the area under the whole curve - which gives the total absorbed energy $\left(\mathrm{W}\left(\mathrm{J} / \mathrm{m}^{3}\right)\right)$ during the test - is used to characterize the compressive behaviour of the MMSFs. Therefore the effect of the chemical composition of the matrix material, the effect of the applied microballoons and the influence of the heat treatment and test temperature on the characterizing properties mentioned above were investigated, pursued and detailed in the next paragraphs. The averages of the measured properties and their scatterings are listed in Table 5, in the following sections the trends of the effects are shown by average graphs for better understanding and for cleaner presentation.

\subsection{The effect of the chemical composition of the matrix and the influence of the type of microballoons}

During the compression tests in annealed condition and at room temperature the MMSFs with Al99.5 matrix showed the smallest strength. The lack of alloying caused low strength, high fracture strain, low structural stiffness and in overall: more plastic behaviour (see Fig. 4). The AICu5 matrix SFs proved to be the strongest and showed the highest compressive strength compared to the Al99.5 matrix SFs ( $+37 \%$ and +47 $\%$ in the case of SL150 and SL300 microballoons, respectively) due to the existing solid-solution strengthening mechanism. Beside the highest strength the AICu5 matrix SFs have the highest structural stiffness and the lowest fracture strain; 
therefore they behaved the most rigid way. This can be also traced on their graphs containing numerous smaller drops in the plateau region, suggesting that many smaller cracks appeared during the compression. The next strongest were AIMgSi12 and AISi12 with almost the same strength. In the case of AIMgSi1 alloy the hardening effect was similar to the Cu alloying (solid-solution strengthening) and caused some increment in the strength $(+11 \%$ and $+16 \%$ compared to Al99.5-SL150 and Al99.5SL300 respectively), but not as much as the more effective $\mathrm{Cu}$. The AlMgSi1 based MMSFs showed almost as rigid behaviour as the AICu5 matrix SFs and because of their lower compressive and plateau strength they absorbed significantly lower mechanical energy (about $-13 \%$ in the case of both microballoon types). In the case of $\mathrm{Si}$ alloying the increment was caused by the relatively high amount of $\mathrm{Si}$ alloying, however the result became almost the same as in the case of AlMgSi1 matrix $(+7 \%$ and $+14 \%$ compared to Al99.5-SL150 and Al99.5-SL300 respectively). This proved that pure Si alloying is not as much effective than $\mathrm{Mg}$ and $\mathrm{Si}$ alloying together. This main difference between the two strengthening mechanisms was also confirmed by the fracture strain. In the case of AIMgSi1 matrix the fracture strain was small due to the stronger strengthening mechanism, while in the case of AISi12 larger fracture strain was recorded, despite the higher amount of alloying elements. In summary the compressive strength followed the trend that is shown by the UTS of the matrix materials (see Table 1). The matrix has decisive effect on the compressive properties of the MMSFs, but not as significant as in the case of pure metals: the changes were much more moderate (compare the differences in Tables 1 and 5). The fracture strain was inversely proportional; it was decreased if the compressive strength increased. The structural stiffness varied in accordance to the strength and strain: if the strength was high and the strain was low the stiffness became higher. The absorbed 
mechanical energy varied between wide ranges due to the different shapes of the plateau region (between point $E$ and $F$ in Fig. 2.) corresponding to the different fracture histories. Therefore it is hard to tell any thumb rule about its trend but in general the higher compressive strength resulted in higher plateau strength and higher absorbed energy. According to the results detailed above, the application of alloyed matrix is justified and gives the advantage to tailor the compressive properties of the MMSFs. It is worth to mention here that the ceramic microballoons with proper coating could be used as a source of alloying elements in MMSF systems. The appropriate choice and concentration of alloying element in the surface coating of the microballoons can enhance the properties of the MMSFs economically.

The type of the microballoons influenced the compressive strength, the fracture strain and the structural stiffness only. Compared to the larger SL300 type, the smaller SL150 type microballoons gave higher compressive strength (+3-10\%), lower fracture strain (-4-20\%) and usually higher structural stiffness $(+5-25 \%$, except in the case of AICu5 matrix: $-5 \%$ ). As it is shown in Table 2 the SL150 microballoons are significantly smaller and they also have thinner wall. The smaller diameter and higher curvature give higher compressive strength and mechanical stability to the microballoons. Moreover, smaller wall thickness ensures lower probability for deflections (see Fig. 5a); therefore the small SL150 microballoons have higher strength than the larger, SL300 type microballoons with thicker walls and more defects (see Fig. 5b.). 


\subsection{The effect of heat treatment}

In the case of heat treatable aluminium alloys the T6 treatment ensures much higher strength compared to the annealed condition. This would be very useful in the case of MMSFs too, because stronger MMSFs can absorb higher amount of mechanical energy and they can be more effective as collision dampers or vehicle hulls. The recorded diagrams are shown in Fig. $6 a$ and $6 \mathrm{~b}$. The T6 heat treatment caused $\sim 10$ $\%$ and $\sim 15 \%$ higher compressive strength in the case of AlMgSi1 and AlCu5 matrix respectively, which is significantly less than expected. This could be caused by some chemical reactions between the microballoons and matrix materials, detailed in another papers $[8,9,37]$. For example the liquid aluminium can reduce the $\mathrm{SiO}_{2}$ content of the microballoons, the exchange reaction is:

$-4 \mathrm{Al}_{(\mathrm{liq})}+3 \mathrm{SiO}_{2(\mathrm{sol})} \rightarrow 2 \mathrm{Al}_{2} \mathrm{O}_{3(\mathrm{sol})}+3 \mathrm{Si}_{(\mathrm{sol})}$

Formázott: Tabulátorok: $16 \mathrm{~cm}$ Jobbra zárt

aAs a result the wall of the microballoon was damaged and pure $\mathrm{Si}$ is dissolved and precipitated inte the matrix material (the maximal solubility of $\mathrm{Si}$ in $\mathrm{Al}$ is $\sim 1,5 \mathrm{wt} \%$ at $\left.\sim 577^{\circ} \mathrm{C}[38]\right)$. This phenomenon was confirmed by the results of XRD measurements (Table 6). From Table 6 the presence of the above mentioned chemical exchange reaction is clear. The amorphous $\mathrm{SiO}_{2} \underline{\text { content }}_{\text {was reduced and }}$ $\underline{\mathrm{Al}_{2}} \underline{ }_{2} \underline{\mathrm{O}_{3}}$ was formed as $\alpha-\mathrm{Al}_{2} \underline{ }_{3}$, os as $\gamma-\mathrm{Al}_{2} \underline{\mathrm{O}}_{3}$, while Si was dissolved and precipitated in the matrix material. This diffusion reaction is induced by the Si concentration mismatch between the material of microballoons and the matrix. However, the reaction has not taken place in the case of AISi12 matrix, because its high Si content. This smallexample shows that these reactions can seriously modify the chemical composition of the matrix, and therefore the applied T6 heat treatment parameters were not the best, they should be further optimized-(about the interfacial reactions in 
details refer to our previous paper [37]]). The interfacial reaction also confirmed by line-EDS measurements. For example the results of AIMgSi1-SL150 MMSF are shown in Fig. 7. The BSE image on the left shows a part of a microballoon (right side in the image). The measuring line was perpendicular to the outer surface of the microballoon. Near to the microballoon's surface (for example in the vicinity of point A) Si precipitations can be observed. The graph on the right in Fig. 7 shows the chemical element composition along the measured line. Between point $\mathrm{B}$ and $\mathrm{C}$ a relatively wide 2-4 $\mu \mathrm{m}$ zone can be observed, within this zone the $\mathrm{Al}$ and the $\mathrm{O}$ content changed smoothly (about the interfacial reactions in details refer to our previous paper [37]). As the strength increased the fracture strain and the structural stiffness also increased a little bit (less than $+5 \%$ in all cases). Due to the higher fracture strain, the MMSFs became more ductile, the first crack appears later and this can be useful in numerous applications. Beside the strengthening mechanism due to heat treatment the dissolved and precipitated Si particles also have effect on the mechanical properties, mainly on the stiffness.

Considering microballoon size Ithe SL300 microballoons performed less again, exactly as it is detailed in the previous section.

\subsection{The effect of elevated temperature}

In Fig. 7 8 the diagrams of Al99.5 and AlSi12 MMSFs compressed at room and at elevated $\left(220^{\circ} \mathrm{C}\right)$ temperature are shown and compared. Due to the elevated temperature the compressive strength dropped by $\sim 30-35 \%$ in the case of all matrices and microballoon types. The formability increased significantly and due to 
this dual effect the transformed strength between the matrix and the microballoons increased slower than at room temperature and the first fracture appeared only later. In one word: the fracture strain increased by $\sim 5-10 \%$ in all cases. The MMSFs became more ductile, but they remained strong enough and can be applied as structural elements: the compressive strengths were still above $120 \mathrm{MPa}$. This capability at elevated temperature is a serious advantage compared to the conventional metal and polymer foams and makes the MMSFs good choice for structural parts in the neighbourhood of combustion engines or other heat producing systems. The absorbed energies were also decreased, due to the lower compressive strength induced lower plateau strength.

The effect of the microballoons' type was the same at elevated temperature too. The MMSFs with SL300 type microballoons showed $~ 5 \%$ lower compressive strength.

\section{Conclusions}

From the results of the above mentioned and discussed measurements the following conclusions can be drawn:

- The typical compression diagram of the MMSFs can be divided into three main parts containing five sections. The peak strength (compressive strength), its strain (fracture strain), the structural stiffness and the area below the graph (the absorbed mechanical energy) can be applied as characterizing values of the compressive behaviour.

- The smaller, SL150 type microballoons ensured higher compressive strength, higher fracture strain and higher structural stiffness than the larger SL300 
microballoons in any circumstances. Beside the higher curvature and therefore higher compressive strength, the thinner wall of the smaller microballoons contains fewer defects, than the thicker wall of the larger ones. The difference between the properties of MMSFs with SL150 and SL300 microballoons is about $5-10 \%$.

- The T6 heat treatment of AIMgSi1 and AICu5 matrix syntactic foams was successful, but the strength increment was much smaller than expected ( 5$10 \%$ instead of $50-100 \%)$. This could be caused by chemical reactions between the constituents, which modified the composition of the matrix and therefore the applied temperature parameters during T6 treatment were not the best and they should be optimized.

- The increased test temperature caused $\sim 30 \%$ drop in the compressive strength, while the fracture strain increased by $\sim 10 \%$. The structural stiffness decreased, thus the MMSF was more ductile than at room temperature. The decrease of compressive strength is significant, but not too large; therefore the MMSFs can be applied as structural elements at elevated temperatures.

In summary the compressive properties of MMSFs can be tailored by proper selection of the materials and by careful design for individual and unique applications.

\section{Acknowledgements}

The Metal Matrix Composites Laboratory is supported by Grant \# GVOP 3.2.1-200404-0145/3.0. This paper was supported by the János Bolyai Research Scholarship of 
the Hungarian Academy of Sciences. The investigations were supported by The Hungarian Research Fund, NKTH-OTKA PD 83687. This work is connected to the scientific program of the " Development of quality-oriented and harmonized $R+D+I$ strategy and functional model at BME" project. This project is supported by the New Széchenyi Plan (Project ID: TÁMOP-4.2.1/B-09/1/KMR-2010-0002). Thanks to C. H. Erbslöh Hungaria Ltd. and R. Tóth for providing the E-spheres.

\section{References}

[1] Babcsan N, Leitlmeier D, Banhart J. Metal foams—high temperature colloidsPart I. Ex situ analysis of metal foams. Colloids and Surfaces A: Physicochemical and Engineering Aspects. 2005;261(1-3):123-30.

[2] Babcsán N, Moreno FG, Banhart J. Metal foams—High temperature colloidsPart II: In situ analysis of metal foams. Colloids and Surfaces A: Physicochemical and Engineering Aspects. 2007;309(1-3):254-63.

[3] Erikson R. A survey of current technology. 5th Aerospace Materials. Von Braun Center, Huntsville, Alabama2002.

[4] Orbulov IN, Dobránszky J. Producing metal matrix syntactic foams by pressure infiltration. Periodica Polytechnica Mechanical Engineering. 2008;52(1):35-42.

[5] Sphere Services Inc, http://wwwsphereservicescom/, last accessed: 25th March 2011.

[6] Envirospheres Ltd, http://wwwenvirospherescom/productsasp, last accessed: 28th November 2011. 
[7] Palmer R, Gao K, Doan T, Green L, Cavallaro G. Pressure infiltrated syntactic foams-Process development and mechanical properties. Materials Science and Engineering: A. 2007;464(1-2):85-92.

[8] Balch D, Odwyer J, Davis G, Cady C, Grayiii G, Dunand D. Plasticity and damage in aluminum syntactic foams deformed under dynamic and quasi-static conditions. Materials Science and Engineering A. 2005;391(1-2):408-17.

[9] Balch D, Dunand D. Load partitioning in aluminum syntactic foams containing ceramic microspheres. Acta Materialia. 2006;54(6):1501-11.

[10] Rohatgi PK, Guo RQ, Iksan H, Borchelt EJ, Asthana R. Pressure infiltration technique for synthesis of aluminum-fly ash particulate composite. Materials Science and Engineering A. 1998;244:22-30.

[11] Rohatgi P, Kim J, Gupta N, Alaraj S, Daoud A. Compressive characteristics of A356/fly ash cenosphere composites synthesized by pressure infiltration technique. Composites Part A: Applied Science and Manufacturing. 2006;37(3):430-7.

[12] Kiser M, He MY, Zok FW. The mechanical response of ceramic microballoon reinforced aluminum matrix composites under compressive loading. Acta Materialia. 1999;47(9):2685-94.

[13] Wu G, Dou Z, Sun D, Jiang L, Ding B, He B. Compression behaviors of cenosphere-pure aluminum syntactic foams. Scripta Materialia. 2007;56(3):221-4. [14] Tao XF, Zhang LP, Zhao YY. Al matrix syntactic foam fabricated with bimodal ceramic microspheres. Materials \& Design. 2009;30(7):2732-6.

[15] Tao XF, Zhao YY. Compressive behavior of Al matrix syntactic foams toughened with Al particles. Scripta Materialia. 2009;61(5):461-4. 
[16] Zhang LP, Zhao YY. Mechanical Response of Al Matrix Syntactic Foams Produced by Pressure Infiltration Casting. Journal of Composite Materials. 2007;41(17):2105-17.

[17] Mondal DP, Das S, Ramakrishnan N, Uday Bhasker K. Cenosphere filled aluminum syntactic foam made through stir-casting technique. Composites Part A: Applied Science and Manufacturing. 2009;40(3):279-88.

[18] Mondal DP, Das S, Jha N. Dry sliding wear behaviour of aluminum syntactic foam. Materials \& Design. 2009;30(7):2563-8.

[19] Rabiei A, Oneill A. A study on processing of a composite metal foam via casting. Materials Science and Engineering: A. 2005;404(1-2):159-64.

[20] Ramachandra M, Radhakrishna K. Synthesis-microstructure-mechanical properties-wear and corrosion behavior of an Al-Si (12\%)—Flyash metal matrix composite. Journal of Materials Science. 2005;40(22):5989-97.

[21] Ramachandra M, Radhakrishna K. Effect of reinforcement of flyash on sliding wear, slurry erosive wear and corrosive behavior of aluminium matrix composite. Wear. 2007;262(11-12):1450-62.

[22] Daoud A. Synthesis and characterization of novel ZnAl22 syntactic foam composites via casting. Materials Science and Engineering: A. 2008;488(1-2):281-95. [23] Couteau O, Dunand D. Creep of aluminum syntactic foams. Materials Science and Engineering: A. 2008;488(1-2):573-9.

[24] Bardella L, Genna F. Elastic design of syntactic foamed sandwiches obtained by filling of three-dimensional sandwich-fabric panels. International Journal of solids and Structures. 2001;38:307-33.

[25] Bardella L, Genna F. On the elastic behavior of syntactic foams. International Journal of solids and Structures. 2001;38:7235-60. 
[26] Marur P. Effective elastic moduli of syntactic foams. Materials Letters. 2005;59(14-15):1954-7.

[27] Marur PR. Influence of imperfect interface on the elastic moduli of syntactic foams. Computational Materials Science. 2009;46(2):327-32.

[28] Sanders WS, Gibson LJ. 2003-Mechanics of hollow sphere foams. Materials Science and Engineering A. 2003;347:70-85.

[29] Trumble KP. Spontaneous infiltration of non-cylindrical porosity Close packed spheres. Acta Materialia. 1998;46(7):2363-7.

[30] Bárczy T, Kaptay G. Modelling the infiltration of liquid metals unto porous ceramics. Materials Science Forum. 2005;473-474:297-302.

[31] Asthana R, Rohatgi PK, Tewari N. Infiltration processing of metal - matrix composites: a review. Processing of Advanced MAterials. 1992;2:1-17.

[32] Jaeger HM, Nagel SR. Physics of the granular state. Science. 1992;5051:152331.

[33] ASM Handbook Volume 4, Heat Treating, Third printing, ASM International, 1995, p 1861-1960.

[34] Testing of metallic materials - Compression test of metallic cellular materials, DIN50134 standard, October 2008.

[35] Gupta N, Kishore, Woldesenbet E, Sankaran S. Studies on compressive failure features in syntactic foam material. Journal of Materials Science. 2001;36:4485-91. [36] Bunn P, Mottram JT. Manufacture and compression properties of syntactic foams. Composites. 1993;24(7):565-71.

[37] Orbulov IN, Dobranszky J, Nemeth A. Microstructural characterisation of syntactic foams. Journal of Materials Science. 2009;44(15):4013-9. 
[38] Binary Alloys Phase Diagrams, Second Edition, ASM International, 1990, p 211 213. 
Table captions

Table 1. Chemical composition and comparative UTS of the applied matrix materials

\begin{tabular}{lcccccccc}
\hline Matrix & \multicolumn{9}{c}{ Main components $(\mathrm{wt} \%)$} & Closest ASM & \multicolumn{2}{c}{ UTS } & Density \\
& $\mathrm{Al}$ & $\mathrm{Si}$ & $\mathrm{Mg}$ & $\mathrm{Cu}$ & equivalent & $\mathrm{O}$ & $\mathrm{T6}$ & $\left(\mathrm{gcm}^{-3}\right)$ \\
\hline Al99.5 & 99.5 & - & - & - & Al1050 & 75 & - & 2.70 \\
AlSi12 & 86 & 12 & - & - & $\mathrm{A} 413$ & 115 & - & 2.65 \\
AlMgSi1 & 97 & 1 & 1.2 & 0.3 & Al6061 & 125 & 310 & 2.70 \\
AlCu5 & 95 & - & - & 4.5 & Al2011 & 190 & 390 & 2.78 \\
\hline
\end{tabular}

Table 2. Morphological properties and phase constitution of the applied hollow ceramic spheres (provided by the manufacturer, except the chemical composition, measured by XRD [37])

\begin{tabular}{|c|c|c|c|c|c|c|c|}
\hline \multirow{3}{*}{ Type } & \multirow{3}{*}{$\begin{array}{c}\text { Bulk } \\
\begin{array}{c}\text { Density } \\
\text { density (at }\end{array} \\
64 \text { vol\% } \%) \\
\left(\mathrm{g} / \mathrm{cm}^{3}\right)\end{array}$} & \multicolumn{2}{|c|}{ Average } & \multirow{3}{*}{$\mathrm{Al}_{2} \mathrm{O}_{3}$} & \multirow[b]{2}{*}{$\frac{\text { Amorphous }}{\mathrm{SiO}_{2}}$} & \multirow[b]{2}{*}{ Mullite } & \multirow{3}{*}{ Quartz } \\
\hline & & diameter & thickness & & & & \\
\hline & & $(\mu \mathrm{m})$ & $(\mu \mathrm{m})$ & & \multicolumn{2}{|c|}{$w t \%$} & \\
\hline SL150 & 0.576 & 100 & 3.69 & & & 19 & 1 \\
\hline SL300 & 0.691 & 150 & 6.75 & $30-35$ & $45-50$ & 19 & 1 \\
\hline
\end{tabular}

Table 3. Density and porosity values of the prepared MMSFs

\begin{tabular}{lccccc}
\hline \multirow{2}{*}{ Specimen } & \multicolumn{3}{c}{ Density $\left(\mathrm{g} / \mathrm{cm}^{3}\right)$} & \multicolumn{3}{c}{ Porosity $(\%)$} \\
\cline { 2 - 6 } & $\begin{array}{c}\text { Theoretical, } \\
\rho_{\mathrm{t}}\end{array}$ & $\begin{array}{c}\text { Measured, } \\
\rho_{\text {meas }}\end{array}$ & $\begin{array}{c}\text { Microballon, } \\
\mathrm{P}_{\mathrm{mb}}\end{array}$ & $\begin{array}{c}\text { Matrix, } \\
\mathrm{P}_{\mathrm{m}}\end{array}$ & $\begin{array}{c}\text { Total, } \\
\mathrm{P}_{\mathrm{t}}\end{array}$ \\
\hline Al99.5-SL150 & 1.34 & 1.43 & 50.9 & -6.3 & 44.7 \\
Al99.5-SL300 & 1.41 & 1.52 & 48.2 & -7.2 & 41.0 \\
AISi12-SL150 & 1.32 & 1.31 & 50.9 & 0.8 & 52.0 \\
AISi12-SL300 & 1.40 & 1.37 & 48.2 & 2.1 & 50.1 \\
AIMgSi1-SL150 & 1.34 & 1.42 & 50.9 & -5.6 & 45.3 \\
AIMgSi1-SL300 & 1.41 & 1.51 & 48.2 & -5.9 & 42.3 \\
AICu5-SL150 & 1.37 & 1.43 & 50.9 & -4.2 & 46.7 \\
AICu5-SL300 & 1.44 & 1.50 & 48.2 & -6.0 & 42.2 \\
\hline
\end{tabular}


Table 4. Parameters of the applied T6 heat treatments

\begin{tabular}{lccccc}
\hline \multirow{2}{*}{ Matrix } & \multicolumn{2}{c}{ Solution treatment } & Cooling & \multicolumn{2}{c}{ Aging } \\
& temperature $\left({ }^{\circ} \mathrm{C}\right)$ & time $(\mathrm{h})$ & medium & temperature $\left({ }^{\circ} \mathrm{C}\right)$ & time $(\mathrm{h})$ \\
\hline AlMgSi1 & 520 & 1 & water & 170 & 14 \\
AlCu5 & 500 & 1 & water & 160 & 14 \\
\hline
\end{tabular}

Table 5. Properties of the investigated MMSFs

\begin{tabular}{lcccc}
\hline Designation & $\begin{array}{c}\text { Compressive } \\
\text { strength } \\
(\mathrm{MPa})\end{array}$ & $\begin{array}{c}\text { Fracture } \\
\text { strain } \\
(\%)\end{array}$ & $\begin{array}{c}\text { Structural } \\
\text { stiffness } \\
(\mathrm{MPa})\end{array}$ & $\begin{array}{c}\text { Absorbed } \\
\text { energy } \\
\left(\mathrm{J} / \mathrm{m}^{3}\right)\end{array}$ \\
\hline Al99.5-SL150-O-20 & $169 \pm 6.5$ & $6.83 \pm 0.099$ & $29.6 \pm 0.56$ & $3765 \pm 50.7$ \\
Al99.5-SL300-O-20 & $154 \pm 1.7$ & $6.57 \pm 0.219$ & $23.9 \pm 0.06$ & $4681 \pm 80.6$ \\
AISi12-SL150-O-20 & $181 \pm 6.7$ & $6.60 \pm 0.318$ & $28.4 \pm 0.21$ & $5805 \pm 75.3$ \\
AISi12-SL300-O-20 & $176 \pm 3.1$ & $6.45 \pm 0.054$ & $22.1 \pm 0.48$ & $3226 \pm 110.8$ \\
AIMgSi1-SL150-O-20 & $187 \pm 5.9$ & $3.65 \pm 0.195$ & $67.8 \pm 2.92$ & $5132 \pm 133.7$ \\
AlMgSi1-SL300-O-20 & $179 \pm 3.3$ & $3.05 \pm 0.104$ & $63.9 \pm 3.95$ & $3461 \pm 132.8$ \\
AICu5-SL150-O-20 & $232 \pm 0.3$ & $3.20 \pm 0.078$ & $82.3 \pm 0.21$ & $5761 \pm 122.6$ \\
AICu5-SL300-O-20 & $227 \pm 3.9$ & $3.00 \pm 0.222$ & $86.3 \pm 3.33$ & $4776 \pm 119.1$ \\
AIMgSi1-SL150-T6-20 & $199 \pm 2.4$ & $4.13 \pm 0.322$ & $71.3 \pm 1.91$ & $3861 \pm 113.7$ \\
AIMgSi1-SL300-T6-20 & $184 \pm 6.2$ & $3.62 \pm 0.234$ & $64.0 \pm 0.95$ & $3521 \pm 149.7$ \\
AICu5-SL150-T6-20 & $248 \pm 7.9$ & $3.25 \pm 0.225$ & $85.3 \pm 2.68$ & $5587 \pm 129.5$ \\
AICu5-SL300-T6-20 & $244 \pm 5.9$ & $3.15 \pm 0.189$ & $88.3 \pm 1.76$ & $6380 \pm 133.6$ \\
AI99.5-SL150-O-220 & $127 \pm 6.8$ & $7.30 \pm 0.212$ & $21.8 \pm 0.84$ & $4320 \pm 77.9$ \\
Al99.5-SL300-O-220 & $123 \pm 4.4$ & $6.60 \pm 0.297$ & $22.4 \pm 0.36$ & $4316 \pm 26.1$ \\
AISi12-SL150-O-220 & $136 \pm 1.6$ & $7.03 \pm 0.161$ & $21.5 \pm 0.40$ & $3439 \pm 73.6$ \\
AISi12-SL300-O-220 & $130 \pm 7.8$ & $7.12 \pm 0.520$ & $21.3 \pm 0.77$ & $2766 \pm 78.8$ \\
\hline
\end{tabular}

Table 6. Phase constitution of MMSFs according to XRD measurements (wt\%)

\begin{tabular}{lccccccc}
\hline Specimen & $\mathrm{Al}$ & $\mathrm{Si}$ & Mullite & $\alpha-\mathrm{Al}_{2} \mathrm{O}_{3}$ & $\mathrm{Y}-\mathrm{Al}_{2} \mathrm{O}_{3}$ & $\begin{array}{c}\mathrm{Amorphous}_{\mathrm{SiO}_{2}} \\
\mathrm{CuAl}_{2}\end{array}$ \\
\hline Al99.5-SL150 & 67 & 8 & 11 & 3 & 11 & 0 & - \\
Al99.5-SL300 & 70 & 7 & 11 & 2 & 10 & 0 & - \\
AlSi12-SL150 & 72 & 7 & 13 & 0 & 0 & 8 & - \\
AlSi12-SL300 & 72 & 7 & 12 & 0 & 0 & 9 & - \\
AlMgSi1-SL150 & 60 & 7 & 8 & 0 & 25 & 0 & - \\
AlMgSi1-SL300 & 60 & 6 & 6 & 0 & 28 & 0 & - \\
AlCu5-SL150 & 60 & 6 & 8 & 8 & 12 & 0 & 6 \\
AlCu5-SL300 & 60 & 5 & 10 & 7 & 12 & 0 & 6 \\
\hline
\end{tabular}


Figures and their captions

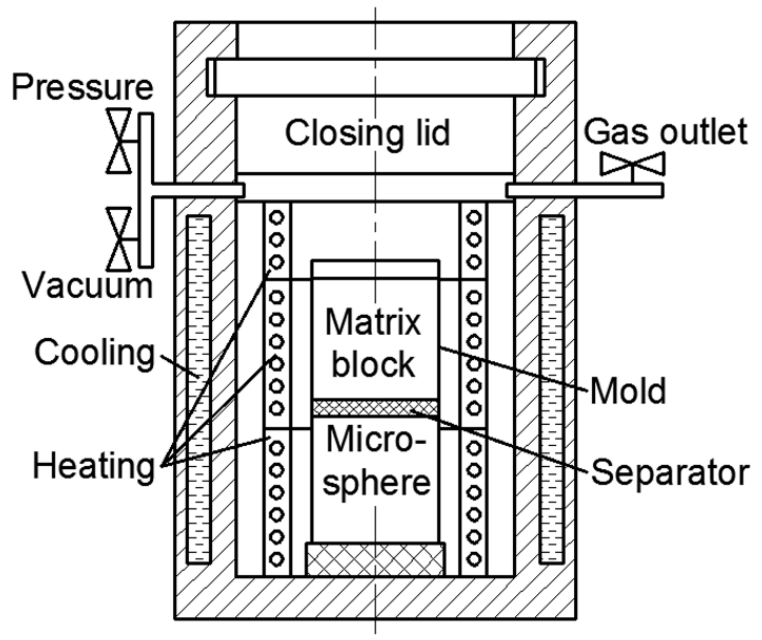

Fig. 1. Schematic sketch of the infiltration chamber 


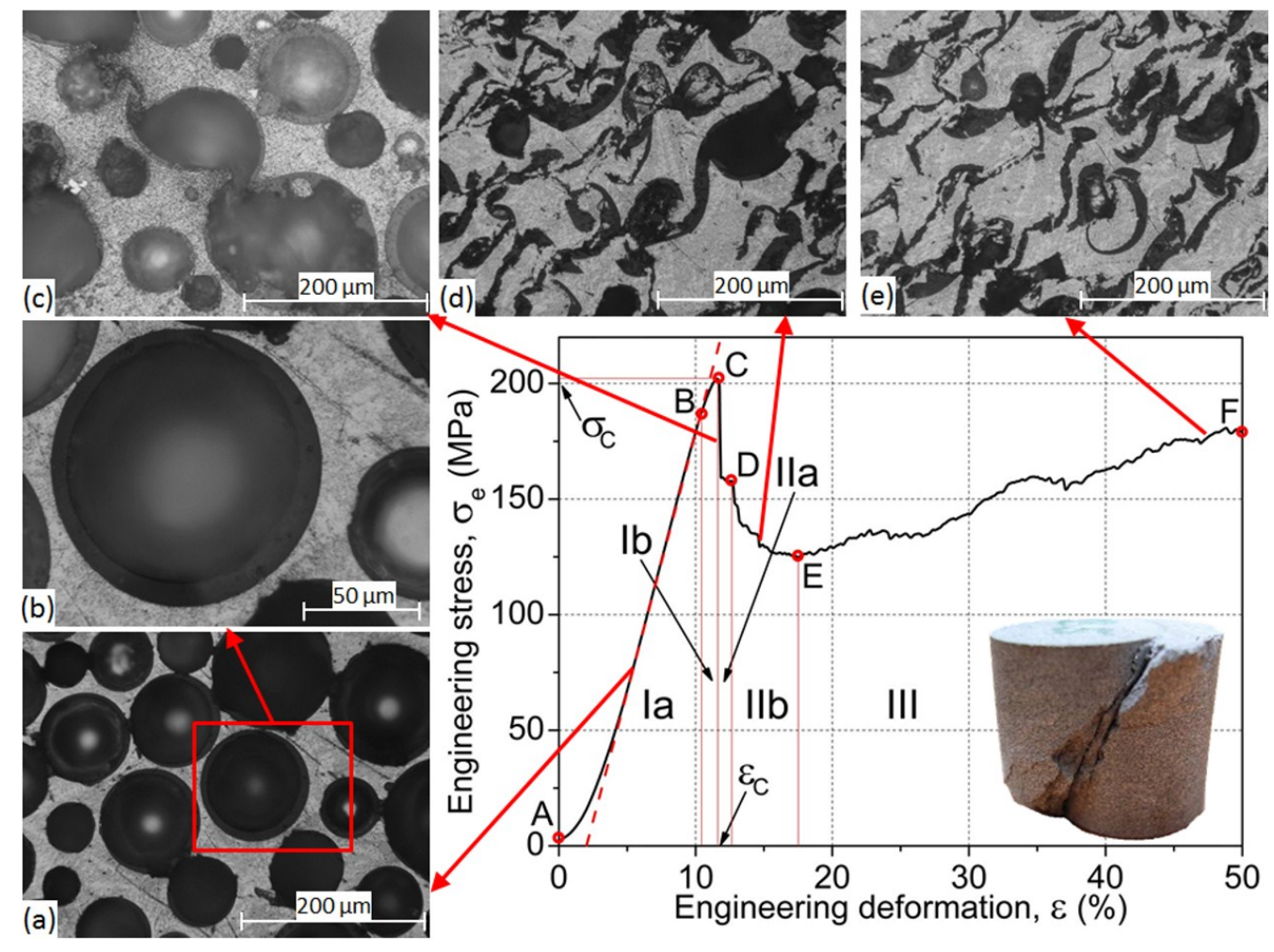

Fig. 2. Typical compressive diagram of AIMgSi1-SL150 MMSF specimen and the broken specimen (bottom right corner) 


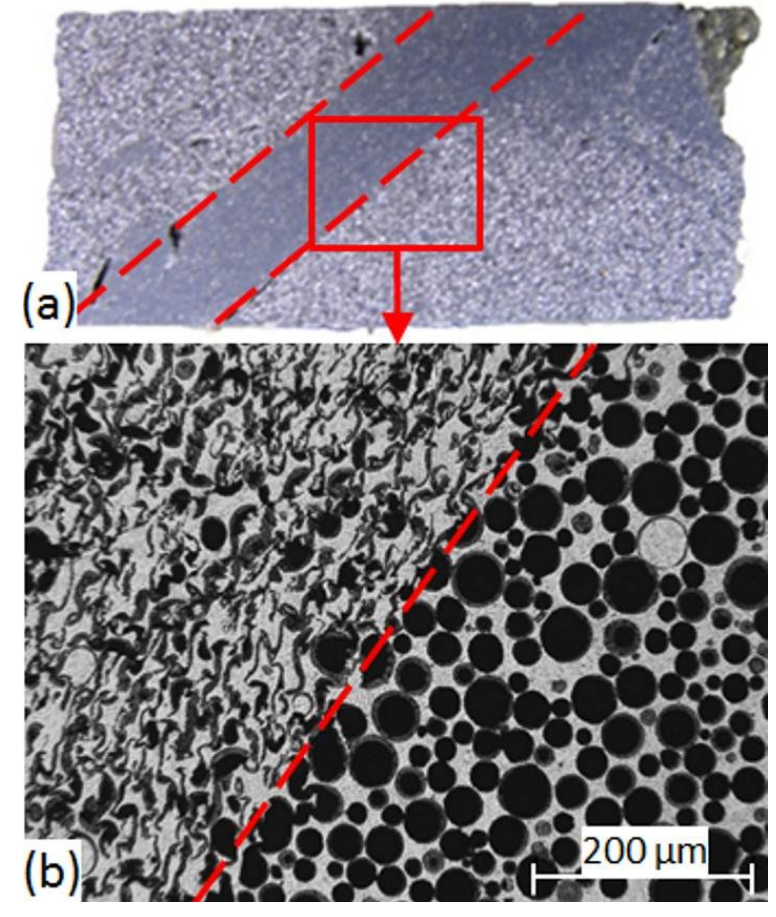

Fig. 3. Grinded specimen after compressed to $50 \%$ engineering strain showing wide shear band (between dashed lines) (a) and magnified optical microscopy image about the margin between the densified and unharmed regions (b) 

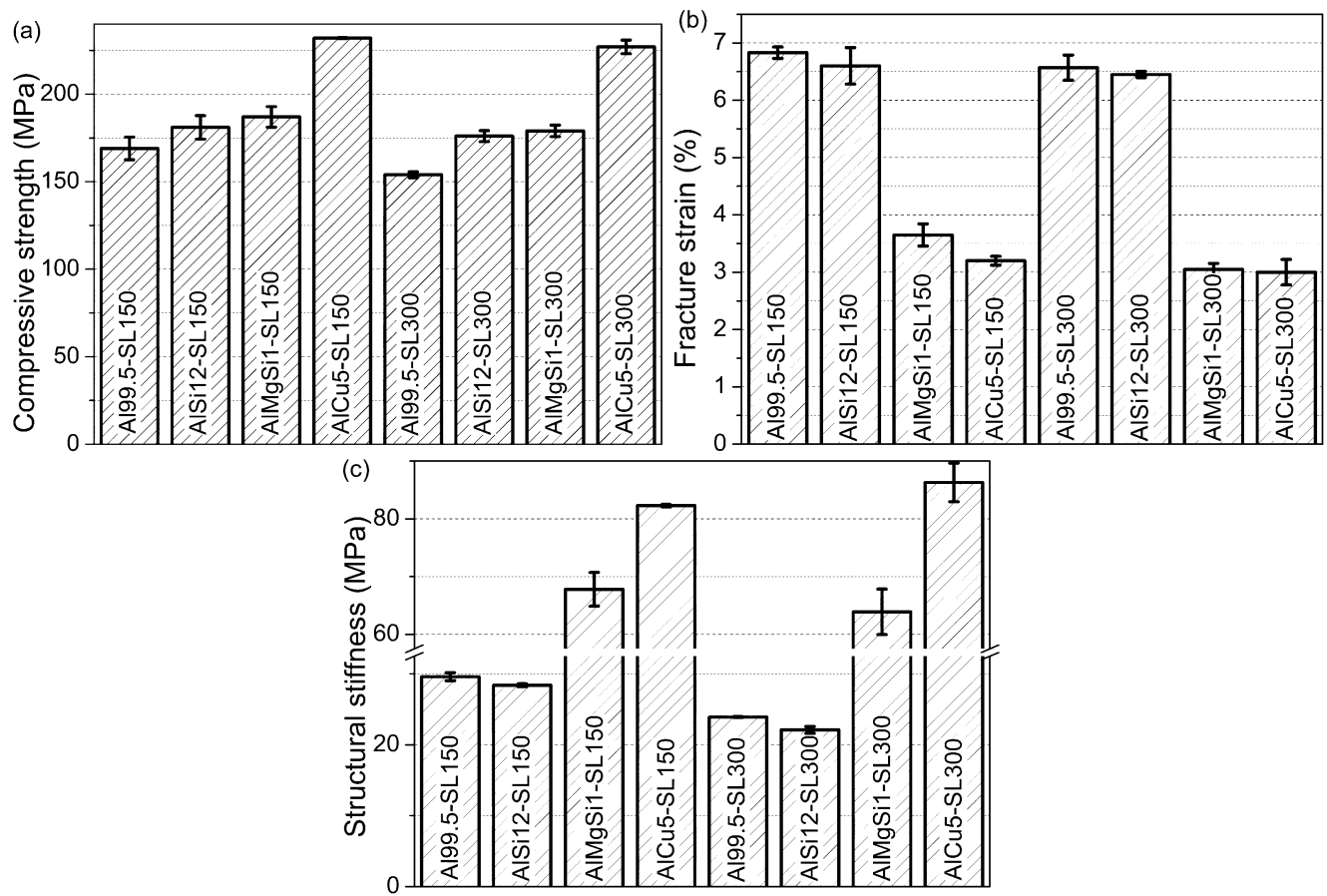

Fig. 4. The effect of the matrix material and microballoon type on the (a) compressive strength, (b) fracture strain and (c) structural stiffness of MMSFs in annealed condition 

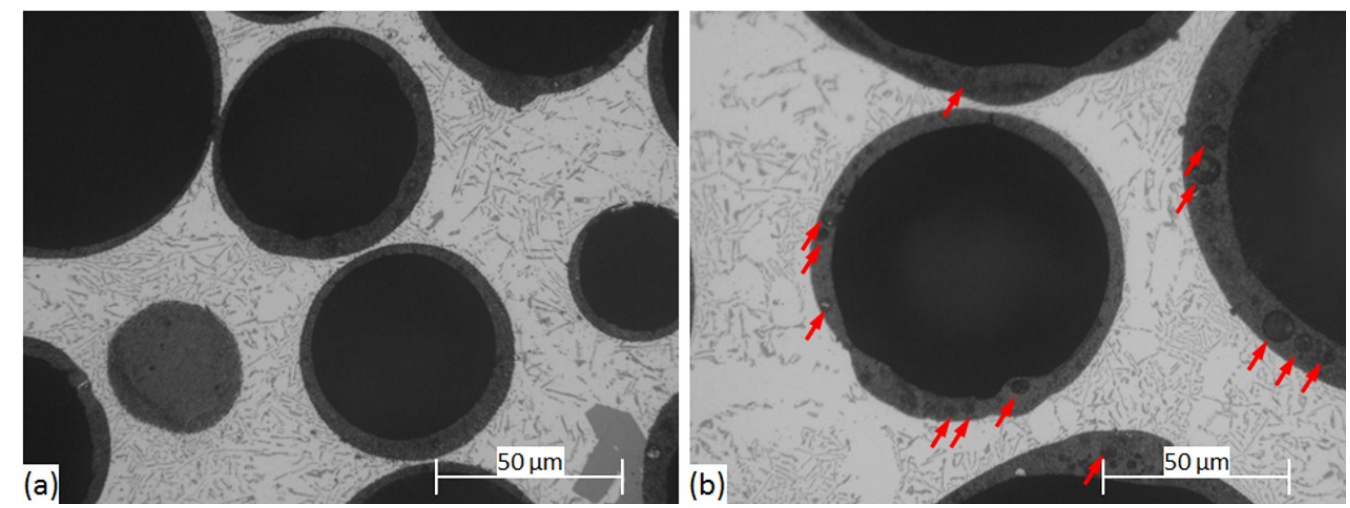

Fig. 5. Representative optical microscopic images about AISi12 matrix SFs

containing (a) SL150 type microballoons with very thin and flawless walls and (b) SL300 type microballoons with thicker wall and many defects (arrows) 


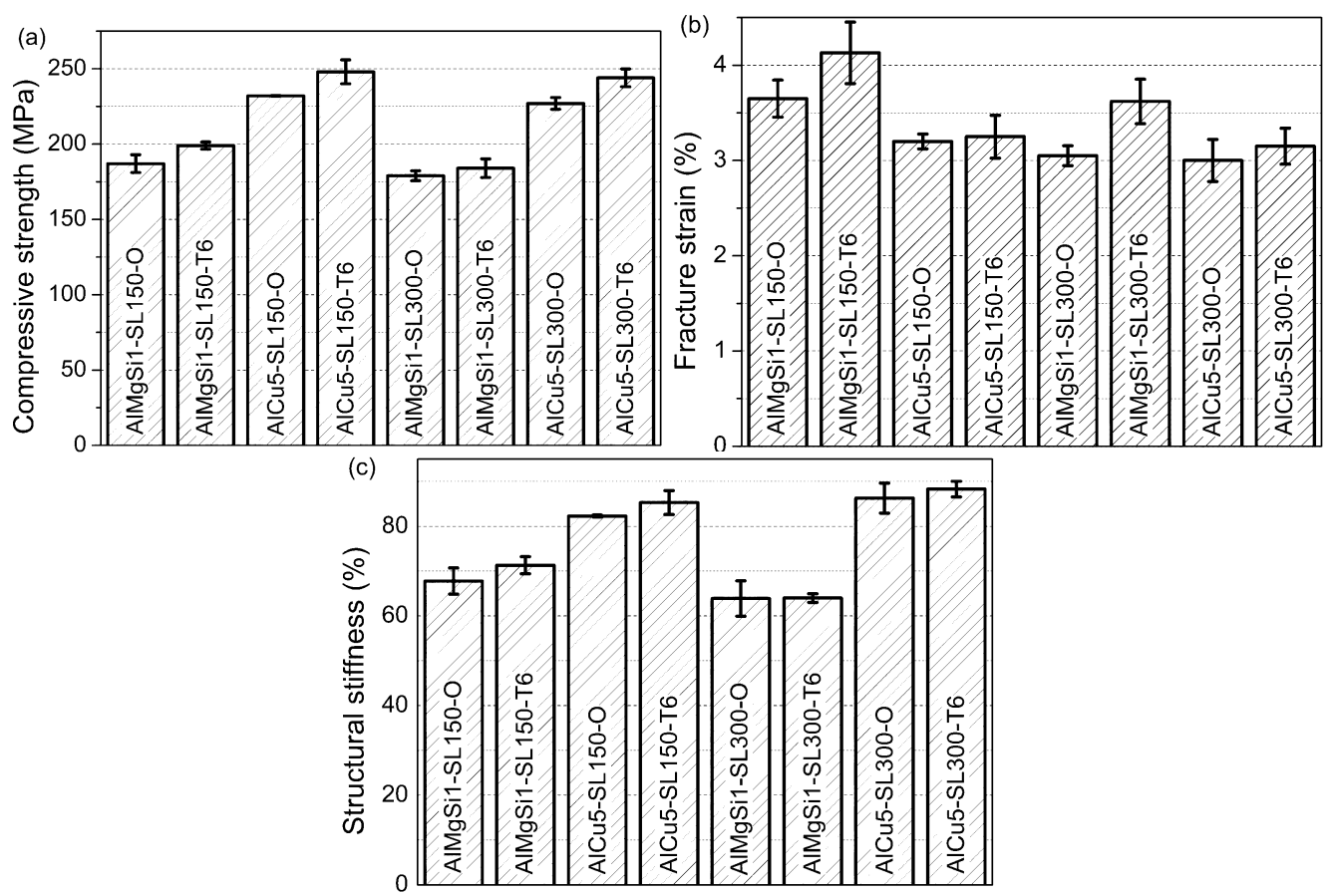

Fig. 6. The effect of heat treatment on the (a) compressive strength, (b) fracture strain and (c) structural stiffness of MMSFs $(\mathrm{O}=$ annealed, $\mathrm{T} 6=\mathrm{T} 6$ heat treated $)$. 


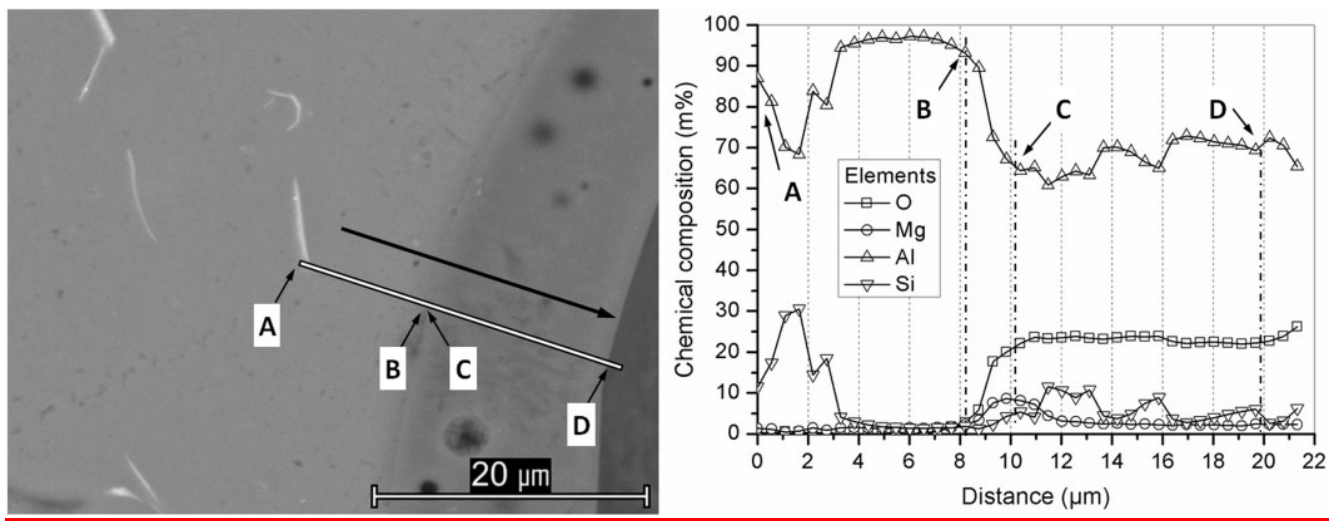

Fig. 7. BSE image and EDS line-scan profiles of the AIMgSi-SL150 syntactic foam

Formázott: Balra zárt 


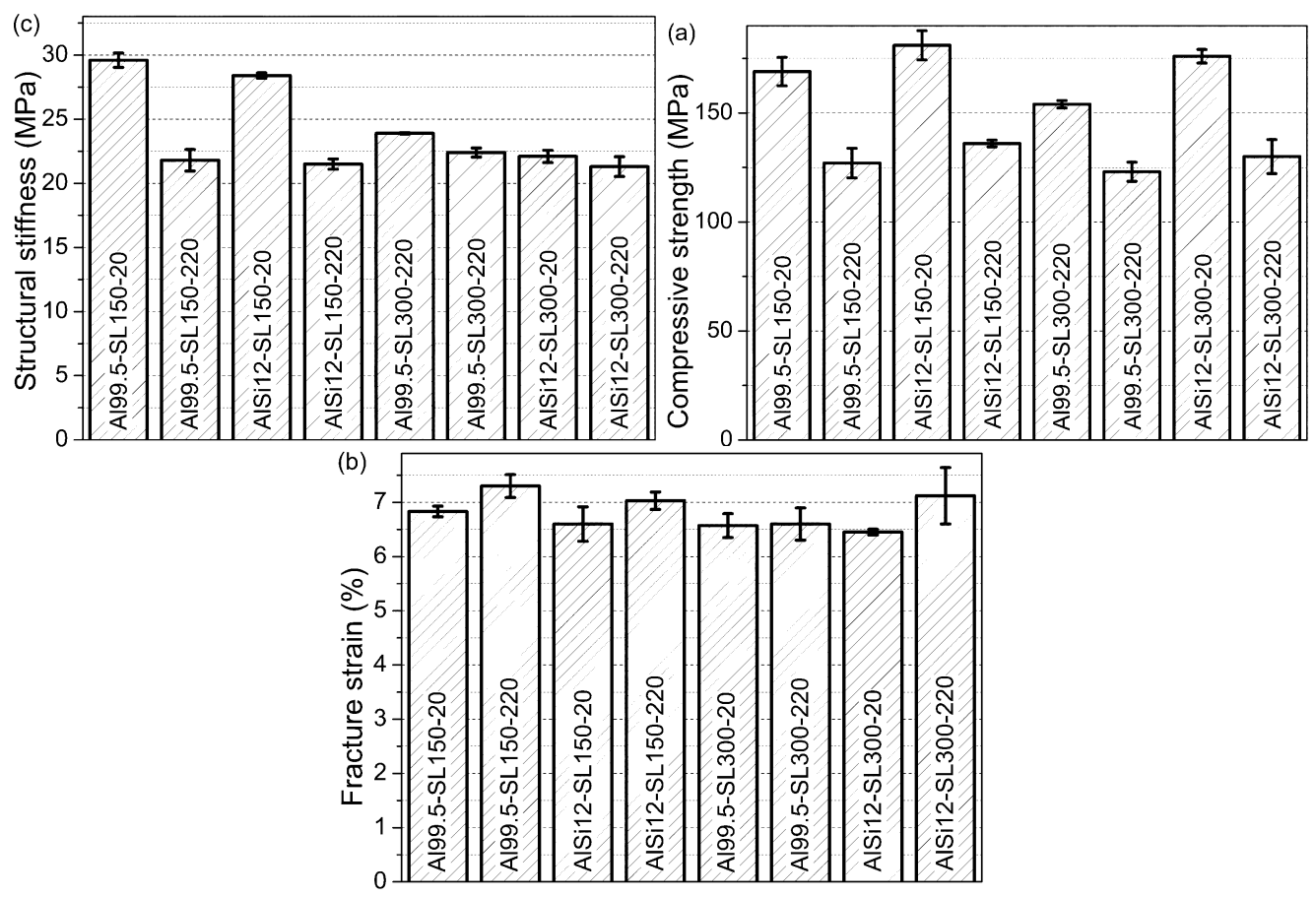

Fig. 7․ The effect of test temperature on the (a) compressive strength, (b) fracture strain and (c) structural stiffness of MMSFs 